\title{
THE DIAGNOSTIC USE OF THE McGILL PICTURE ANOMALY TEST IN TEMPORAL LOBE EPILEPSY
}

\author{
BY \\ DENIS C. SHALMAN \\ From the Department of Psychology, Institute of Psychiatry, and the Guy's-Maudsley Neurosurgical \\ Unit, Maudsley Hospital, London
}

In 1958, Milner applied the McGill picture anomaly test to patients with temporal lobe epilepsy and reported certain dysfunctions in patients with epileptic disturbances of the non-dominant hemisphere. This test had been prepared by Hebb and Morton (1943) and the results obtained from using it formed the basis for Hebb's (1939) conclusions regarding the defects that followed a right temporal lobectomy, namely, a disturbance of capacities not concerned with language. Precisely what the test measures is not known, but Milner suggests that, in addition to the trait which Hebb mentions, it involves pictorial comprehension and visual identification, and it is these functions that she attributes to the right temporal lobe. Dr. Milner reported her observations on 50 subjects with lesions in the temporal lobe.

A systematic investigation has been carried out at the Guy's-Maudsley Neurosurgical Unit to determine validity of the McGill picture anomaly series as a diagnostic tool.

\section{Subjects}

The 21 subjects were patients of the Guy's-Maudsley Neurosurgical Unit. Every epileptic patient admitted to the unit for temporal lobectomy over the past two years was included in the sample, and this was the only selection factor. All were tested before and one month after a unilateral anterior temporal lobectomy of about 6 to $7 \mathrm{~cm}$. extent. The resection (performed by Mr. Murray A. Falconer) included the mesial structures, consisting of the hippocampus, uncus, and amygdaloid nucleus, and extended on the surface backwards to Labbe's vein. The decision as to which side was operated was made largely on E.E.G. criteria (Falconer, Hill, Meyer, Mitchell, ands Pond, 1955).

\section{Tests}

The McGill picture anomaly test (Hebb and Morton 1943) consists of two highly correlated forms $(r=0.93$ 을 each containing a total of 34 pictures, each of which has some incongruous feature. The test is not a verbal one + the instructions, ('show me what is funny or out of place' being kept to a minimum. The subject must identify @iN anomaly by pointing, and the correctness of the response and the time scores are recorded. All patients receiped Form $M$ before operation and Form $N$ after
lobectomy.

The untimed version of the progressive matriees (Raven, 1938), a non-verbal test of intelligence, was used? to assess the level of cognitive functioning independent of the speed of performance. Form I of the Wechsteres Bellevue intelligence scale was also administered preoperatively.

\section{Results}

The patients were divided into three groups (1) Right-handed patients with a left temporaP lobectomy; (2) right-handed patients with a righ $\overrightarrow{\widehat{C}}$ temporal lobectomy; (3) left-handed patients with lobectomy on either right or left side. The group have been equated for age, sex, and the full-scale. I.Q. (Table I) and it can therefore be assumed that they form a homogeneous sample. Only patient

TABLE I

OPERATIVE GROUPING

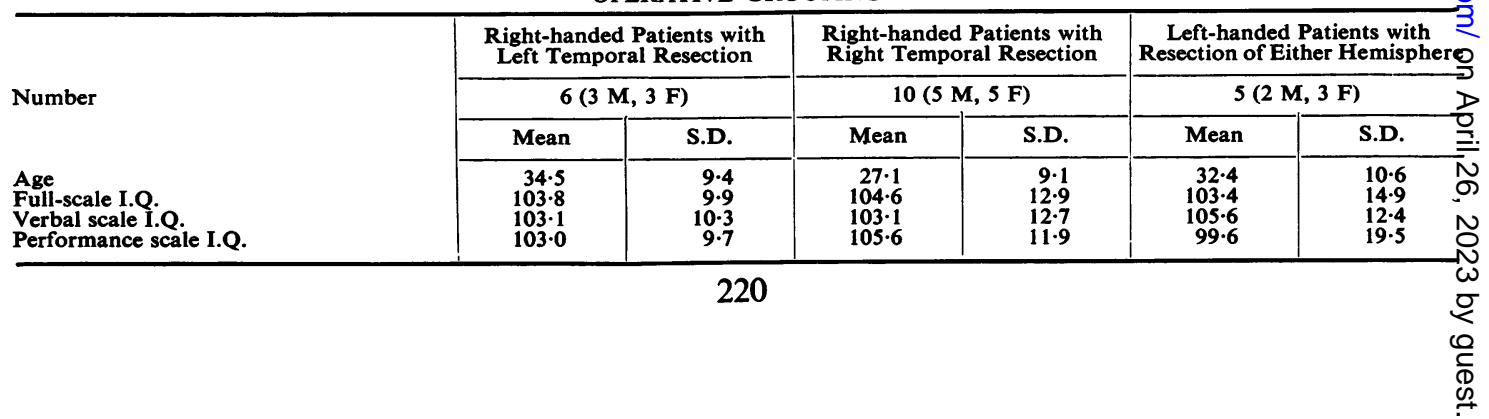


TABLE II

RESULTS OF MCGILL PICTURE ANOMALY TEST WITH ERROR AND TIME SCORE BEFORE AND AFTER UNILATERAL LOBECTOMY

\begin{tabular}{|c|c|c|c|c|c|c|}
\hline & \multicolumn{2}{|c|}{$\begin{array}{l}\text { Right-handed Patients with } \\
\text { Left Temporal Resection }\end{array}$} & \multicolumn{2}{|c|}{$\begin{array}{l}\text { Right-handed Patients with } \\
\text { Right Temporal Resection }\end{array}$} & \multicolumn{2}{|c|}{$\begin{array}{l}\text { Left-handed Patients with } \\
\text { Resection of Either Hemisphere }\end{array}$} \\
\hline & Mean & S.D. & Mean & S.D. & Mean & S.D. \\
\hline $\begin{array}{l}\text { Error } \\
\text { Pre-operative } \\
\text { Post-operative } \\
\text { Time }\end{array}$ & $\begin{array}{r}8 \cdot 3 \\
11 \cdot 3\end{array}$ & $\begin{array}{l}4 \cdot 1 \\
5 \cdot 2\end{array}$ & $\begin{array}{r}8 \cdot 3 \\
11 \cdot 0\end{array}$ & $\begin{array}{l}3.9 \\
5.4\end{array}$ & $\begin{array}{l}10 \cdot 0 \\
11 \cdot 0\end{array}$ & $\begin{array}{l}2 \cdot 8 \\
2 \cdot 3\end{array}$ \\
\hline $\begin{array}{l}\text { Pre-operative } \\
\text { Post-operative }\end{array}$ & $\begin{array}{l}8 \cdot 5 \\
9 \cdot 7\end{array}$ & $\begin{array}{l}2 \cdot 7 \\
2 \cdot 6\end{array}$ & $\begin{array}{r}9 \cdot 4 \\
10 \cdot 6\end{array}$ & $\begin{array}{l}3 \cdot 5 \\
2 \cdot 7\end{array}$ & $\begin{array}{l}12 \cdot 1 \\
10 \cdot 5\end{array}$ & $\begin{array}{l}4 \cdot 4 \\
2 \cdot 1\end{array}$ \\
\hline
\end{tabular}

TABLE III

PRE-OPERATIVE SCORES ON RAVEN'S PROGRESSIVE MATRICES AND ON FULL-SCALE I.Q. OF WECHSLER-BELLEVUE INTELLIGENCE SCALE

\begin{tabular}{|c|c|c|c|c|c|c|}
\hline \multirow[b]{3}{*}{$\begin{array}{l}\text { Full scale } \\
\text { Progressive matrices }\end{array}$} & \multicolumn{2}{|c|}{$\begin{array}{l}\text { Right-handed Patients with } \\
\text { Left Temporal Resection }\end{array}$} & \multicolumn{2}{|c|}{$\begin{array}{l}\text { Right-handed Patients with } \\
\text { Right Temporal Resection }\end{array}$} & \multicolumn{2}{|c|}{$\begin{array}{l}\text { Left-handed Patients with } \\
\text { Resection of Either Hemisphere }\end{array}$} \\
\hline & Mean & S.D. & Mean & S.D. & Mean & S.D. \\
\hline & $\begin{array}{l}103 \cdot 8 \\
107 \cdot 3\end{array}$ & $\begin{array}{r}9 \cdot 9 \\
12 \cdot 3\end{array}$ & $\begin{array}{r}104 \cdot 6 \\
96 \cdot 2\end{array}$ & $\begin{array}{r}12 \cdot 9 \\
4 \cdot 5\end{array}$ & $\begin{array}{l}103 \cdot 4 \\
114 \cdot 0\end{array}$ & $\begin{array}{l}14 \cdot 9 \\
10 \cdot 2\end{array}$ \\
\hline
\end{tabular}

with an abnormality in one temporal lobe, as determined by pre-operative electroencephalography, are included in this study (Falconer et al., 1955). The discrepancy between the verbal and performance scale scores is not significant for either the left temporal lobe or the right temporal lobe group.

Analysis of the McGill picture anomaly test indicates that neither error nor time scores differentiate the left temporal from the right temporal lobe groups on pre-operative testing (Table II). On post-operative testing, both groups were found to increase their error scores to the same extent, and thus they cannot be differentiated on this basis. Furthermore, no increase in time scores was manifested on post-operative testing, and so this measure also fails to discriminate between the groups.

As can be seen from Table II, there were five lefthanded patients with resections of one or the other temporal lobe. This left-handed group had slightly higher error scores than either of the right-handed groups before lobectomy, but the difference is not statistically significant. The time scores for the lefthanded group were significantly higher $(P<0.01)$ than for both the right-handed groups before surgery, but the post-operative results were not significant. The results obtained from this small sample tend to differentiate the left-handers as a group from the right-handers. A similar conclusion is reached when the discrepancy between the verbal and performance scores are examined (Table I); only the left-handed group showed a performance score lower than the verbal score, but the difference was slight.

The left-handed group is admittedly small. However, they score significantly differently from righthanded patients on some tests and for this reason have been classified separately. The method of selecting handedness was determined by hand preference for everyday tasks excluding writing. In only one patient was an attempt made to relate handedness to cerebral dominance. This was done by a bilateral intracarotid injection of sodium amytal and in this instance dysphasia was produced by the left intracarotid injection (Wada and Rasmussen, 1960). It might be argued that some of the group were 'converted sinistrals' but there is no evidence to suggest this. Since the contralateral hemisphere is speech dominant in only half of the cases in left-handed patients (Humphrey and Zangwill, 1952), and because of the incomplete history on the handedness of the patients and their ancestors, it was decided to treat them as a separate group.

Analysis of the intelligence test scores (Table III) indicates that patients with disturbance of the right temporal lobe score significantly lower $(P<0.01)$ on the matrices than on the Wechsler tests. Patients who subsequently underwent a left temporal lobectomy scored slightly higher on the matrices than on the Wechsler tests, but this does not achieve an acceptable level of significance.

\section{Discussion}

These results on the McGill picture anomaly test do not support the prediction that patients with abnormalities in the right temporal lobe will be inferior on error and time scores to the left temporal lobe group. Contrary to Milner's prediction, the time scores did not increase significantly following lobectomy on either side. Furthermore, increases in error score were the same for both groups. Thus 
Milner's results are not supported in our somewhat smaller sample, and this casts doubt on the assumption that the test has a diagnostic value of the kind suggested by Milner.

It might, of course, be argued that cultural influences between North American and British patients could have masked real differences of the kind which Milner predicted, but this seems unlikely. It may, however, be appropriate to note that patients are referred to the Montreal Unit mainly for epileptic symptoms, whereas patients at the Guy's-Maudsley Unit probably offer a greater incidence of psychiatric disorders.

Milner does not comment upon the relationship between the right and left temporal lobe groups on the McGill picture anomaly test and only briefly mentions that 'the right temporal lobe patients make significantly more errors $(P<0.01)$ both before and after the operation than other brain-injured subjects'. She does not elaborate on the category of 'brain-injured subjects', and it seems likely that this was a heterogeneous group with widespread lesions involving the frontal and parietal regions which could cause a marked degree of skewness to the results. It would seem reasonable that when a particular function is credited to the right temporal lobe it is necessary to show that the left temporal lobe is not involved to the same degree.

When discussing the Wechsler-Bellevue scale, Milner stresses the inferior performance of patients with right temporal lobe lesions on non-verbal tests, and cites the decline of the scores on the performance scale as evidence. This particular finding was not confirmed in the present investigation. However, it seems possible that if this were true it could account for the results on the McGill picture anomaly test; the non-verbal element is common to both tests and seems to be the most likely differentiator of right temporal and left temporal lobe cases.

Raven's progressive matrices is an excellent nonverbal intelligence test and correlates highly with the Wechsler-Bellevue test (Hall, 1957). The progressive matrices test was included pre-operatively to assess the importance of the non-verbal factor, and analysis indicates $(P<0.01)$ that the test discriminates not only the right from the left temporal lobe (in righthanded subjects) but also the left-handed group from the right-handed group. It appears, therefore, that its non-verbal nature is important; or, as Hebb (1939) originally stated, 'the removal from the right temporal lobe was followed by a disturbance non-language capacities'.

Left-handed patients are seldom reported in the literature, and since little is known about the neuroe anatomical and physiological relationships of the group, it has usually been set aside and not cond sidered in psychological studies. However, for the tests employed on this occasion, it was the onl group to demonstrate significant differences for laterality of lesion and operative interference. Conclusions on this group must remain tentative, but 莠 appears that the group is more resistant to detr $\vec{b}$ mental effects produced by a temporal lobectomy More will be said about this group in a late publication.

\section{Summary and Conclusions}

An analysis of the McGill picture anomaly tes $\vec{P}$ suggests that its use as a diagnostic test for lateralit $\vec{\psi}$ of a lesion in temporal lobe epileptics is not supg ported. Contrary to Milner's (1958) predictions the test did not differentiate patients with right tempora lobe disorders from patients with left temporal lobe disorders. Possibly the observations of Milner equ be accounted for in terms of the right temporal lobs being important for performance on non-ver, tasks. The progressive matrices test was included to assess this supposition, and it discriminated at a hegh level of significance between patients with disorders in the right temporal lobe and patients with the geif temporal lobe involved. Left-handed patients, group, tended to obtain scores significantly differentio from right-handed patients on the psychometrie tests both pre-operatively and post-operatively.

Financial support for this project was provided by $\sum_{\text {a }}$ grant from the Bethlem Royal Hospital and the Maudsle Hospital Research Fund. The author is indebted t 8 Professor H. J. Eysenck and Mr. Murray A. Falconeen for their advice and interest in this investigation, and $t \overrightarrow{\mathrm{C}^{+}}$ the Guy's-Maudsley Neurosurgical Unit which provide $\$$ the facilities.

\section{REFERENCES}

Falconer, M. A., Hill, D., Meyer, A., Mitchell, W., and Pond, D. (1955). Lancet, 1, 827.

Hall, J. C. (1957). J. cons. Psychol., 21, 23.

Hebb, D. O. (1939). J. gen. Psychol., 21, 437.

Hebb, D. O. (1939). J. We (1943). J. educ. Psychol., 34, 16.

Humphrey, M. E., and Zangwill, O. L. (1952). J. Neurol. Neurosuro Psychiat., 15, 184.

Milner, B. (1958). Res. Publ. Ass. nerv. ment. Dis., 36, 244.

Raven, J. C. (1938). Guide to Using Progressive Matrices. Lewiß̧,

Wada, J., and Rasmussen, T. (1960). J. Neurosurg., 17, 266.

.

